\title{
Right ventricular involvement in Tako-tsubo cardiomyopathy - insights from cardiovascular magnetic resonance
}

\author{
Caroline Scally*, Christopher J Neil, Janaki Srinivasan, Baljit Jagpal, Bernice K Ng, Michael P Frenneaux, \\ John Horowitz, Dana K Dawson
}

From 18th Annual SCMR Scientific Sessions

Nice, France. 4-7 February 2015

\section{Background}

It has been recently suggested that patients with Takotsubo cardiomyopathy (TTC) who exhibit right ventricular (RV) involvement at Echocardiography may have a worse prognosis. The aim of the current study was to prospectively evaluate the extent of RV involvement acutely and at follow up using gold-standard cardiac magnetic resonance (CMR).

\section{Methods}

21 patients, mean age 66 (range 41-87 years) with a clear diagnosis of TTC (14 with ST-elevation, 16 with apical ballooning ) and emotional trigger were prospectively studied. CMR-derived LV and RV volumes and EF, RV shapes, RV wall motion index (WMSI, 6-segment model) and Echocardiography derived Pulmonary artery pressure (Pap), tricuspid annular E', $\mathrm{A}^{\prime}, \mathrm{S}^{\prime}$, pansystolic excursion (TAPSE) were measured acutely (day $0-3$ ) and after 4 months follow-up.

\section{Results}

Eleven patients demonstrated RV involvement on CMR in contrast, RV wall motion abnormalities were identified in only 6 patients on Echocardiography Patients were grouped according to the "acute" RV-WMSI on CMR: WMSI $=1$ (Group A, $\mathrm{n}=10$ ) and WMSI $>1$ (Group B, $\mathrm{n}=11$ ).

In the acute phase, LVEF was significantly lower in Group B compared with Group A $(48 \pm 10 \%$ vs $62 \pm 6 \%$, $\mathrm{p}=0.02$ ), but this did not reach statistical significance for RVEF ( $58 \pm 13 \%$ vs $65 \pm 7 \%$, p=ns). However, Pap was significantly higher acutely in Group B compared to Group A $(40 \pm 15 \mathrm{mmHg}$ vs $28 \pm 6 \mathrm{mmHg}, \mathrm{p}=0.04)$. There were no significant differences between Groups for RV volumes (raw and indexed), E', A', S' or TAPSE.

At follow-up, LVEF improved significantly in both groups $(62 \pm 6 \%$ to $66 \pm 6 \%$ in Group $A, p=0.01$ and 48 $\pm 10 \%$ to $63 \pm 6 \%$ in Group B, $\mathrm{p}<0.01)$. Pap decreased significantly in Group B (from $40 \pm 15$ to $28 \pm 8, \mathrm{p}=0.018$ ). RV-WMSI normalized in all but one in Group B.

\section{Conclusions}

CMR detected RV involvement in $52 \%$ of patients presenting with acute TTC vs only $29 \%$ detected on Echocardiography and should be used as a gold-standard. WMSI and Pap are the best markers to identify these patients.

\section{Funding}

Grant:G13/10 from Tenovus Scotland.

Published: 3 February 2015

\section{doi:10.1186/1532-429X-17-S1-P280}

Cite this article as: Scally et al:: Right ventricular involvement in Takotsubo cardiomyopathy - insights from cardiovascular magnetic resonance. Journal of Cardiovascular Magnetic Resonance 2015 17(Suppl 1): P280.

Cardiology, University of Aberdeen, Aberdeen, UK 